pag

Business School

WORKING PAPER SERIES

Working Paper

2013-036
Are Stock Prices Related to Political Uncertainty Index in OECD Countries? Evidence from Bootstrap Panel Causality Test

Tsangyao Chang

Wen-Yi Chen

Rangan Gupta

Duc Khuong Nguyen

http://www.ipag.fr/fr/accueil/la-recherche/publications-WP.html

IPAG Business School

184, Boulevard Saint-Germain

75006 Paris

France 


\title{
Are Stock Prices Related to Political Uncertainty In- dex in OECD Countries? Evidence from Bootstrap Panel Causality Test
}

\author{
Tsangyao Chang \\ Department of Finance, Feng Chia University, Taichung, Taiwan
}

Email: tychang@fcu.edu.tw

Wen-Yi Chen

Center of Health Research and Development

National Taichung University of Science and Technology, Taichung, Taiwan

Email: chenwen@nutc.edu.tw

\section{Rangan Gupta}

Department of Economics, University of Pretoria, Pretoria, 0002, South Africa

Email: rangan.gupta@up.ac.za

\author{
Duc Khuong Nguyen* \\ IPAG Lab, IPAG Business School, France \\ Email: duc.nguyen@ipag.fr
}

\begin{abstract}
This study applies bootstrap panel causality, proposed by Kónya (2006), to investigate causal link between political uncertainty and stock price for seven OECD countries over the monthly period of 2001.01 to 2013.04. This modeling approach allows us to examine both the cross-sectional dependency and the country-specific heterogeneity. Our empirical results indicate that not all the countries are alike and that the theoretical prediction that stock prices fall at the announcement of a policy change is not always supported. Specifically, we find evidence of the stock price leading hypothesis for Italy and Spain, while the political uncertainty leading hypothesis cannot be rejected for the United Kingdom and the United States. In addition, the neutrality hypothesis was supported in the remaining three countries (Canada, France, and Germany), while the feedback hypothesis, however, is never found.
\end{abstract}

Keywords: Stock Price; Political Uncertainty Index; Bootstrap Panel Causality Test JEL Classifications: C23, G12, G18

* Corresponding author. 


\section{Introduction}

Stock prices are among the most important indicators for capital budgeting and portfolio management decisions as they directly reflect companies' financial health and future prospects. The modern finance theory suggests that stock price is determined as the sum of expected future dividends, discounted at the appropriate risk-adjusted discount rates. Accordingly, changes in market participants' expectations about expected cash flows and/or discount rates are likely to drive stock prices over time. A number of studies have investigated the extent to which stock returns are explained by patterns in expected cash flows (Shiller, 1981; Marsh and Merton, 1986; Kothari and Shanken, 1992; Pincus et al., 2007; Hirshleifer et al., 2009; Maio and Santa-Clara, 2013). In most of these studies, expectations of cash flows are frequently proxied by dividend yields, dividend-to-price ratio, and earnings variables (earnings-to-price ratio, and dividend-to-earnings ratio). For instance, Kothari and Shanken (1992) conduct a cross-sectional analysis of aggregate stock return variation using portfolios formed on the basis of annual return performance and find that nearly $90 \%$ of the portfolio return variation is explained by dividend and expected return variables. More recently, Maio and Santa-Clara (2013) examine the predictive ability of dividend yield for future stock returns and dividend growth, and document that the variance decomposition associated with aggregate dividend yield has important influence on the cross-section of stock returns. Their results remain intact when other forecasting horizons, econometric techniques and an alternative decomposition based on excess returns are used.

The past literature has also provided abundant evidence that time variations in stock prices are closely linked to changing structure of risk factors, business cycles, and macroeconomic aggregate fluctuations (Fama and French, 1989; Schwert, 1990; Ferson and Harvey, 1991; Cochrane, 2008; Kang et al., 2011). The main rationale behind this strand of research is that all investors operating in stocks markets around the 
world give a close watch to what happens in the economy as a whole and adjust their expectations and investment decisions. For example, Fama and French (1989) show that expected returns on common stock and long-term bonds contain a term premium that is related to business conditions. This finding amounts to say that expected returns tend to be higher during times of economic recessions, and lower during economic expansions. On the other hand, other studies such as Schwert (1990) and Ferson and Harvey (1991) explain the time-variation in stock prices (returns) using the Arbitrage Pricing Theory developed by Ross (1976). They mainly document a significant short-run link between stock market returns and changes in macroeconomic variables including, among others, inflation, interest rates, industrial production, and the term structure of interest rates. Kang et al. (2011) use the conditioning variable from the cointegrating relation among several macroeconomic variables to derive a conditional version of the consumption capital asset pricing model (CCAPM) and show that the latter performs as well as Fama and French's (1993) three-factor model in explaining the cross-section of the Fama and French 25 size and book-to-market sorted portfolios. ${ }^{1}$

The impact scheduled and unscheduled macroeconomic news announcements on stock returns have been another important topic in the financial economic literature. Flannery and Protopapadagis (2002) assess that these market-wide risk measures affect aggregate stock returns and should be considered as priced factors because they significantly influence the stock price generating processes and, in turn, return distributions. $^{2}$ Likewise, the majority of other studies find evidence to suggest that prices and volatility in various financial markets react substantially and quite instantaneously

\footnotetext{
1 This set of macroeconomic variables includes dividend yield, term spread, default spread, and short-term interest rate.

${ }^{2}$ Flannery and Protopapadagis (2002) identify six candidates for priced factors for stock returns including three nominal (CPI, PPI, and a Monetary Aggregate) and three real (the Balance of Trade, the Employment Report, and Housing Starts).
} 
to macroeconomic news announcements (e.g., Äijö, 2008 for options-implied return distributions; Nikkinen et al., 2006 for stock markets; Balduzzi et al., 2001 for bond markets; Andersen and Bollerslev, 1998 for foreign exchange markets). In particular, Ederington and Lee (1993) study the impact of scheduled macroeconomic news announcements on interest rate and foreign exchange futures markets and find that these announcements are responsible for most of price adjustments and volatility patterns in these markets.

In this article, we join the above-mentioned literature by investigating the causal links between economic policy uncertainty and stock prices for seven countries of the Organization for Economic Co-operation and Development (OECD). Our study is broadly related to studies that examine the determinants of stock price variations over time, and more closely related to studies that concern the interactions between stock returns and macroeconomic variables. For this purpose, we use the economic policy uncertainty index introduced by Baker et al. (2012), which reflects information about media coverage of political uncertainty, tax expiration codes and disagreement among economic forecasters. To the extent that the uncertainty regarding the government intervention in the economy and markets affects consumption, production, economic growth, and company investments, stock prices are likely to respond significantly to changes in the economic policy uncertainty index. The higher the level of uncertainty, the more volatile is the stock market.

Questions regarding whether economic policy uncertainty affects stock prices have recently interested academic researchers and practitioners. ${ }^{3}$ The main motivation arises from the fact that economic policy uncertainties may have greatly contributed to the recent long-swings trend and important instability of stock prices (Baker et

\footnotetext{
3 The impact of economic policy uncertainty on economic growth, inflation, investment and employment has, however, been long discussed in the past literature (e.g., Marcus, 1981; Bernanke, 1983; Dixit, 1989; Rodrik, 1991; Bloom et al., 2007; Bloom, 2009; Bhagat et al., 2013).
} 
al., 2012; Brogaard and Detzel, 2012). Major recent studies tackling this issue provide evidence that the increase in economic policy uncertainty is generally associated with a decline in stock returns and a rise in stock volatility (e.g., Ozoguz, 2009; Dzielinski, 2012; Pástor and Veronesi, 2012; Bhagat et al., 2013; Pástor and Veronesi, 2013; Antonakakis et al., 2013; Kang and Ratti, 2013). For instance, Ozoguz (2009) employs the state probabilities estimated from two-state regime-switching models of aggregate market return and of aggregate output as measures of uncertainty and finds evidence of a negative link between the level of uncertainty and asset valuations. Dzielinski (2012) proposes a new measure of economic uncertainty based on the frequency of internet search and shows that stock returns decrease in the week following an increase in this search-based uncertainty measure, but realized stock volatility increases. The study by Pástor and Veronesi (2012) also concludes on a negative relationship between stock market returns and government policy uncertainty as measured by the variance of policy changes. Antonakakis et al. (2013) look at the dynamic correlations among S\&P 500 market returns, implied volatility, and policy uncertainty index of Baker et al. (2012), and find a negative conditional correlation between market returns and policy uncertainty over time. Moreover, the increase in market volatility leads to higher policy uncertainty. Finally, Kang and Ratti (2013) document that oil price shock and economic policy uncertainty are interrelated and influence stock returns in the United States. In particular, real stock returns decline in response to an unexpected increase in policy uncertainty.

Our article differs from previous literature in two novel ways. First, unlike previous studies which often consider a single country perspective, we examine the existence of cross-sectional dependency between stock prices and political uncertainty as well as heterogeneity across sample OECD countries. As we know that ignoring cross-section dependency leads to substantial bias and size distortions (Pesearan, 
2006), implying that testing for the cross-section dependence is a crucial step in a panel data analysis. Second, our panel causality approach is more advantageous than standard panel approaches in that it enables to examine the country-specific causality by accounting for heterogeneity and cross-sectional dependency. This is particularly important because the standard panel approaches generally provide a statistics that evaluates the causality for the whole panel, but are unable to reveal which cross-sectional unit is potentially driving the results. Our results, drawn from a panel of seven OECD countries over the monthly period of 2001.01 to 2013.04, suggest that the causal relationships between political uncertainty and stock prices differ across countries. While we find evidence the unidirectional causality running from stock prices to political uncertainty for Italy and Spain, and from political uncertainty to stock prices for the United Kingdom and United States, the neutrality hypothesis characterize the nexus between these variables for the rest of the sample countries.

The article proceeds as follows. Section 2 explains the methodology. Section 3 describes the corresponding data and the empirical results. Policy implications are also included in this section. Section 4 concludes the article.

\section{Methodology}

As stated earlier, the purpose of this study is to investigate the causal relationship between stock price and political uncertainty within seven OECD countries (i.e., Canada, France, Germany, Italy, Spain, UK, and the US) over the monthly period of 2001.01-2013.04 by focusing on both panel behavior and country-specific analysis. The method we use to detect the potential causal linkages between stock price and political uncertainty is the so-called the bootstrap panel causality test proposed by Kónya (2006). Compared to traditional causality tests that proceed with testing for the 
unit root first, and then estimate the error correction model in order to examine the Granger causality, the bootstrap panel causality test has several advantages. First, the bootstrap panel causality test can bypass the unit root tests in which the power of the unit root tests is usually weak and the results vary across different testing methods (Kónya, 2006). Second, due to a failure of accounting for both cross-country interrelations and country-specific heterogeneity, the traditional panel error correction model provides a biased estimation in testing the causal relationship between two time series (Pesaran, 2006). Although the bootstrap panel causality test is more sophisticated than traditional causality tests, these are three issues that should be dealt with before proceeding with the bootstrap panel causality test. We present these issues as follows:

\section{i) Cross-sectional dependency}

The first issue in our panel causality analysis is to test the existence of cross-sectional dependence across countries. Pesaran (2006) shows that ignoring cross-section dependency leads to substantial bias and size distortions in estimation and inference of the relationship between two variables. Since a high degree of globalization and market integration makes a country to be sensitive to the economic shocks in other countries, there may exist cross-sectional dependence across these seven OECD countries. Three tests, $C D_{B P}, C D_{L M}$, and $C D$ tests, were used to test the cross-sectional dependence of the data. The $C D_{B P}$ test was proposed by Breusch and Pagan (1980). Under the null hypothesis of no cross-sectional dependence for panel data, the $C D_{B P}$ statistic is asymptotically distributed as chi-square with $N(N-1) / 2$ degrees of freedom, where $N$ represents number of countries.

Note that the $C D_{B P}$ test is only valid for $N$ relatively small and $T$ (time span) sufficiently large (Pesaran, 2004). Hence, Pesaran (2004) proposes a cross-sectional dependency test (the so-called $C D$ test). Under the null hypothesis of no cross- sectional dependence for panel data as $T \rightarrow \infty$ and $N \rightarrow \infty$ in any order, the $C D$ statistic is 
asymptotically distributed as standard normal. Although $C D$ test corrects the drawback of $C D_{B P}$ test when $N$ is large, there are two shortcomings of the $C D$ test addressed in the literature. First, the $C D$ test is subject to decreasing power in a certain situation that the population average pair-wise correlations are zero, although the underlying individual population pair-wise correlations are non-zero (Pesaran et al., 2008). Second, the $C D$ test would fail to reject the null hypothesis in stationary dynamic panel data models when the factor loadings have zero mean in the cross-sectional dimension (Sarafisidis et al., 2009). In order to deal with these problems, Pesaran et al. (2008) proposed a bias-adjusted test which is a modified version of the $C D_{B P}$ test by using the exact mean and variance of the $C D_{B P}$ statistic. Under the null hypothesis of no cross-sectional dependence for panel data with first $T \rightarrow \infty$ and then $N \rightarrow \infty, C D_{L M}$ statistic is also asymptotically distributed as standard normal.

\section{ii) Slope homogeneity}

The second issue in our panel causality analysis is to test whether or not slope coefficients are homogenous in our empirical model. It does not allow us to capture heterogeneity due to country specific characteristics, if the slope homogeneity is assumed without any empirical evidences (Breitung, 2005). In addition, Granger (2003) stated that the causality from one variable to another variable by imposing the joint restriction for whole panel is a strong null hypothesis (Granger, 2003). The standard $F$ test is a common method to test the null hypothesis of slope homogeneity against the alternative hypothesis of slope heterogeneity. Nevertheless, the standard $F$ test is only valid if these conditions, where (i) the cross section dimension $(N)$ is relatively small and the time span $(T)$ of panel is large, (ii) the explanatory variables are strictly exogenous, and (iii) the error variances are homoscedastic, are justified. By relaxing the homoscedasticity assumption (i.e., condition (iii) mentioned above) in the standard $F$ test, Swamy (1970) derives the slope homogeneity test on the dispersion of individual 
slope estimates from a suitable pooled estimator.

Note that both the $F$ and Swamy's tests require panel data models where $N$ is small relative to $T$ (Pesaran and Yamagata, 2008). In order to validate the Swamy's test without any restrictions on the relative expansion rates of $N$ and $T$, the $\tilde{\Delta}$ test was proposed by Pesaran and Yamagata (2008) for testing slope homogeneity in large panels. Under the null hypothesis of slope homogeneity with the condition of $(N, T) \rightarrow \infty$, so long as $\sqrt{N} / T \rightarrow \infty$ and the error terms are normally distributed, the $\tilde{\Delta}$ statistic follows an asymptotic standard normal distribution. The small sample properties of $\tilde{\Delta}$ statistic can be improved under the normally distributed errors by using a bias adjusted statistic $\left(\tilde{\Delta}_{a d j}\right)$ suggested by Pesaran and Yamagata (2008).

\section{iii) Panel Causality Analysis}

The third issue in our panel causality analysis is to deal with both cross-section dependence and slope heterogeneity across sample OECD countries simultaneously. If these two properties of data are found, the bootstrap panel causality test proposed by Kónya (2006) should be used to simultaneously deal with both cross-section dependency and country-specific heterogeneity in testing the causal relationship between political uncertainty and stock prices. The bootstrap panel causality test is based on Seemingly Unrelated Regression (SUR) estimation of the set of equations and the Wald tests with individual country-specific bootstrap critical values. The special feature of the bootstrap panel causality test is that there is no need to pre-test panel unit root and cointegration properties of the data, because country-specific bootstrap critical values are generated in comparison with the Wald statistic. In addition, one can identify which and how many countries exhibit Granger causal relations by imposing country-specific restrictions. The system to be estimated in the bootstrap panel causality approach is displayed as follows: 


$$
\begin{gathered}
y_{1 t}=\alpha_{1}+\sum_{j=1}^{l_{y 1}} \beta_{1 j} y_{1 t-j}+\sum_{j=1}^{l_{x 1}} \delta_{1 j} x_{1 t-j}+\varepsilon_{1 t} \\
y_{2 t}=\alpha_{2}+\sum_{j=1}^{l_{y 1}} \beta_{2 j} y_{2 t-j}+\sum_{j=1}^{l_{x 1}} \delta_{2 j} x_{2 t-j}+\varepsilon_{2 t} \\
: \\
: \\
y_{N t}=\alpha_{N}+\sum_{j=1}^{l_{y 1}} \beta_{N j} y_{N t-j}+\sum_{j=1}^{l_{x 1}} \delta_{N j} x_{N t-j}+\varepsilon_{N t}
\end{gathered}
$$

and

$$
\begin{gathered}
x_{1 t}=\alpha_{1}^{\prime}+\sum_{j=1}^{l_{y 2}} \beta_{1 j}^{\prime} y_{1 t-j}+\sum_{j=1}^{l_{x 2}} \delta_{1 j}^{\prime} x_{1 t-j}+\varepsilon_{1 t}^{\prime} \\
x_{2 t}=\alpha_{2}^{\prime}+\sum_{j=1}^{l_{y 2}} \beta_{2 j}^{\prime} y_{2 t-j}+\sum_{j=1}^{l_{x 2}} \delta_{2 j}^{\prime} x_{2 t-j}+\varepsilon_{2 t}^{\prime} \\
: \\
: \\
x_{N t}=\alpha_{N}^{\prime}+\sum_{j=1}^{l_{y 2}} \beta_{N j}^{\prime} y_{N t-j}+\sum_{j=1}^{l_{x 2}} \delta_{N j}^{\prime} x_{N t-j}+\varepsilon_{N t}^{\prime}
\end{gathered}
$$

where $y=\left[y_{1 t}, y_{2 t}, \ldots, y_{N t}\right]^{\prime}$ and $x=\left[x_{1 t}, x_{2 t}, \ldots, x_{N t}\right]^{\prime}$ denote stock price index and political uncertainty index, respectively. Both $y$ and $x$ were transformed into a natural logarithm scale. $l y(l x)$ is the lag length of $y(x) . \alpha_{i}$ and $\alpha_{i}^{\prime}$ are individual intercepts; $\beta_{i j}$ and $\delta_{i j}\left(\beta_{i j}^{\prime}\right.$ and $\left.\delta_{i j}^{\prime}\right)$ are slope coefficients in Equation [1] (Equation [2]). $\varepsilon_{i t}$ and $\varepsilon_{i t}^{\prime}$ represent residual terms. Equation [1] and Equation [2] are the SUR system because each equation in this system has different predetermined variables while the error terms might be contemporaneously correlated.

We can construct four alternative hypotheses of causal linkages for a country in the system. First, the political uncertainty leading hypothesis means that there is one-way Granger causality from political uncertainty $(x)$ to stock price index $(y)$ if not all $\delta_{i j}$ are zero, but all $\beta_{i j}^{\prime}$ are zero. Second, the stock price leading hypothesis states that there is one-way Granger causality running from stock price index $(y)$ to political uncertainty $(x)$ if all $\delta_{i j}$ are zero, but not all $\beta_{i j}^{\prime}$ are zero. Third, the feed- 
back hypothesis indicates that there is two-way Granger causality between political uncertainty index $(x)$ and stock price index $(y)$ if neither $\delta_{i j}$ nor $\beta_{i j}^{\prime}$ are zero. Fourth, neutrality hypothesis shows there is no Granger causality between political uncertainty $(x)$ and stock price index $(y)$ if all $\delta_{i j}$ and $\beta_{i j}^{\prime}$ are zero. As indicated by Kónya (2006), the results from the bootstrap panel causality test may be sensitive to the lag structure. The selection of optimal lag structure is determined by minimizing Schwarz Bayesian Criterion from 1 to 4 lags (Kónya, 2006).

\section{Data and Empirical Results}

The monthly data used in this study covered the period from 2001.01 to 2013.04 for seven OECD countries: Canada, France, Germany, Italy, Spain, UK, and the US. The sample is restricted to those OECD countries for which data on political uncertainty index introduced by Baker et al. (2012) and stock price index are available. These data were obtained from Baker et al. (2012) and the International Financial Statistics maintained by the International Monetary Fund, respectively. The start and end dates of our sample are governed by data availability to ensure a balanced panel structure. Figure 1 plots the political uncertainty index and stock price index, while the descriptive statistics are presented in Table 1. As we can see, the stock price index varies across these seven OECD countries from 1195.24 (in the United States) to 27402.59 (in Italy) over the period from 2001.01 to 2013.04. The largest price variability is found in Italy, followed by Canada and Spain. In general, the political uncertainty index is more stable than the stock price index in these seven OECD countries. It ranges from 104.17 (in Canada) to 132.56 (in the United Kingdom). We also observe several periods where political policy indices comove with stock prices for some countries: Italy (2009-2010), Spain (2008-2010), and the United Kingdom and the United States 
(2008-2011). For the other countries, there is no evidence of synchronization between these variables over time. Note that the higher the value of the political uncertainty index, the more important is the amount of uncertainty about economic policies, tax code provisions, and divergence of economic forecasts.

\section{【Insert Table 1 here】}

Table 2 displays the empirical results for testing cross-sectional dependency and slope homogeneity. As indicated in Table 2, the values of the three different test statistics $\left(C D_{B P}, C D_{L M}\right.$, and $\left.C D\right)$ are $269.103,38.283$, and 15.568 , respectively, which provide strong evidence to reject the null hypothesis of no cross-sectional dependence between political uncertainty and stock price, across the countries at the $1 \%$ significance level. This finding implies that uncertainty shocks occurred in a particular country is transmitted to other countries, due to a high degree of globalization, market integration, and close economic linkages in the OECD countries.

\section{【Insert Table 2 here】}

Table 2 also reports the results from the slope homogeneity tests, developed by Swamy (1970) and Pesaran and Yamagata (2008). The three different test statistics $\left(\tilde{\Delta}, \tilde{\Delta}_{a d j}\right.$, and Swamy) are $1288.143,8.854$, and 4826.793 , respectively, and they indicate that the null hypothesis of the slope homogeneity is clearly rejected at the $1 \%$ significance level. The rejection of slope homogeneity implies that the panel causality analysis by imposing homogeneity restriction on the variable of interest will result in misleading statistical inferences and thus misleading conclusions on both the strength and direction of causality. In this scheme of things, the direction of causal linkages between stock price and political uncertainty in the seven OECD countries is rather heterogonous, or in other words, the directional causal linkages between the variables of interest may differ across these countries.

Taken together, the existence of cross-sectional dependency and heterogeneity 
across countries suggests the suitability of our empirical framework based on the bootstrap panel causality test. The results from the bootstrap panel causality test, reported in Table 3, confirm this finding effectively. Indeed, the results in Table 3 show that not all the stock price indices are affected by political uncertainty, and vice versa. The stock price leading hypothesis was found only in Italy and Spain at the 1\% and $5 \%$ levels, respectively. For these two countries, the uncertainty about future government actions could increase following market sentiment deteriorations or increased market volatility. To put it differently, by observing stock market movements, investors who are a priori heterogeneous may have different expectations about the policy options, which raise the uncertainty about the policy to adopt. Stock price movements in other countries do not drive the changes in the political uncertainty. On the other hand, the political uncertainty leading hypothesis cannot be rejected in the United Kingdom and the United States, meaning that political uncertainty shocks appear to be a matter of concern for investors in stock markets. It seems that investor community in the United States and the United Kingdom, which is pre-dominated by sophisticated investors (e.g., fund managers, arbitragists, and speculators), gives a heightened weight to the policy option that will be chosen. These findings are thus consistent with those of recent studies for the US markets including Dzielinski (2012), Antonakakis et al. (2013), and Kang and Ratti (2013) where a significant influence of policy uncertainty on stock prices was found. Our results also show that the neutrality hypothesis was supported in the three remaining countries (i.e., Canada, France, and Germany), while the feedback hypothesis, however, is never found in these seven OECD countries over the period from 2001.01 to 2013.04.

\section{【Insert Table 3 here】}

Previous studies investigating the relationship between stock prices and political uncertainty, in general, tends to find a negative relationship between these variables, 
with the impact running from policy uncertainty to stock prices. For example, Dzielinski (2012) constructed an indicator of economic uncertainty from the search volume index (SVI) for the word "economy" provided by Google Trends and documents that a high degree of economic uncertainty is followed by a significant drop of stock returns, a result in favor of the uncertainty leading hypothesis. In addition, Sum (2012) develops a VAR analysis using the EPU index of the United States and shows that an increase in EPU Granger-cause the market returns to drop, a result in support of the political uncertainty leading hypothesis. Note that these two studies investigate the causal relationship between stock price and political uncertainty in a single country (i.e., the United States). Our empirical results regarding the causal relationship in a group of countries from the bootstrap panel causality tests thus complement the findings from these two studies. They are also in line with the two above-mentioned studies, in the sense that it supports the unidirectional causality between stock prices and political uncertainty, particularly for the United States. However, our study contrasts the empirical evidence provided by Kang and Ratti (2013), who find that economic policy uncertainty significantly depresses the real stock returns in Canada, and in Europe (at the regional level).

The implications of our findings differ, across countries. For Italy and Spain, policymakers and market authorities should give heed to stock market sentiment in order to neutralize the possibly negative impact of policy uncertainty on stock markets before an optimal policy choice is made. Inversely, to the extent that the optimal policy option has not only political but also economic costs as pointed out by Pastor and Veronesi, the governments in the United Kingdom and United States should have to reduce their policy decision uncertainty, in particular during periods of economic downturns. 


\section{Conclusion}

The past literature has shown that stock returns and volatility are significantly affected by economic policy uncertainty, in addition to firm-specific characteristics, macroeconomic fundamentals and systematic risk factors. Therefore, market participants in financial markets, whatever the location, pay great attention to the current economic conditions and the prospective economic outlook. The more the macroeconomic environment is uncertain, the more it will be difficult to evaluate the asset price generating processes and to make accurate investment decisions.

In this article, we apply bootstrap panel causality, proposed by Kónya (2006), to investigate causal link between political uncertainty and stock price for 7 OECD countries over the 2001.01 - 2013.04 period by looking at both heterogeneity and cross-sectional dependency, while analyzing country-specific causality. Our empirical results are not always consistent with the empirical evidence provided by past studies because political uncertainty affects stock prices in only two out of seven countries under consideration (Italy and Spain). Likewise, the causality from stock prices to political uncertainty is significant in two other countries (United Kingdom and United States). For the remaining countries, the neutrality hypothesis is retained. These different patterns in the linkages between political uncertainty and stock prices cast doubt about the theoretical proposition that policy uncertainty depresses stock returns through its negative impacts on industrial production, economic growth, and firm-level investment decisions. On the other hand, the absence of significant relations between these variables also leads us to think that they may be linked in a nonlinear and asymmetric manner. Indeed, policy uncertainty may only have significant impact on stock prices when it exceeds a certain level, while its impact can be different depending on whether the stock markets are in bullish or bearish phases. We currently perform this research direction. 


\section{References}

Äijö, J., 2008. Impact of US and UK macroeconomic news announcements on the return distribution implied by FTSE-100 index options. International Review of Financial Analysis 17, 242-258.

Andersen, T., Bollerslev, T., 1998. Deutschmark-dollar volatility, intra-day activity patterns, macroeconomic announcements, and longer-run dependencies. Journal of Finance, 53, 219-265.

Antonakakis, N., Chatziantoniou, I., Filis, G., 2013. Dynamic co-movements between stock market returns and policy uncertainty. Economics Letters 120, 87-92.

Baker, S., Bloom, N., Davis, S., 2012. Measuring economic policy uncertainty. Working Paper Series, Stanford University.

Balduzzi, P., Elton, E.J., Green, T.C., 2001. Economic news and bond prices: evidence from the U.S. Treasury market. Journal of Financial and Quantitative Analysis 36, 523-543.

Bernanke, B.S., 1983. Irreversibility, uncertainty, and cyclical investment. Quarterly Journal of Economics 98, 85-106.

Bhagat, S., Ghosh, P., Rangan, S.P., 2013. Economic policy uncertainty and economic growth in India. Working paper series.

Bloom, N., Bond, S., Reenen, J.V., 2007. Uncertainty and investment dynamics. Review of Economic Studies 74, 391-415.

Bloom, N., 2009. The impact of uncertainty shocks. Econometrica 77, 623-685.

Breusch, T., Pagan, A., 1980. The LM test and its application to model specification in econometrics. Review of Economic Studies 47, 239-254.

Brogaard, J., Detzel, A., 2012. The asset pricing implications of government economic policy uncertainty. University of Washington mimeo.

Dzielinski, M., 2012. Measuring economic uncertainty and its impact on the stock market. Finance Research Letters 9, 167-175.

Ederington, L.H., Lee, J.H., 1993. How markets process information: News releases and volatility. Journal of Finance 48, 1161-1191.

Ferson, W., Harvey, C., 1991. The variation of economic risk premiums. Journal of Political Economy 99, 385-415.

Flannery, M., Protopapadagis, A., 2002. Macroeconomic factors do influence aggregate stock returns. Review of Financial Studies 15, 751-782. 
Hirshleifer, D., Hou, K., Teoh, S.H., 2009. Accruals, cash flows, and aggregate stock returns. Journal of Financial Economics 91, 389-406.

Kang, W., Ratti, R.A., 2013. Oil shocks, policy uncertainty and stock market returns. Journal of International Financial Markets, Institutions and Money 26, 305-318.

Kónya, L., 2006. Exports and growth: Granger causality analysis on OECD countries with a panel data approach. Economic Modelling 23, 978-992.

Kothari, S., Shanken, J., 1997. Book-to-market, dividend yield, and expected market returns: A time-series analysis. Journal of Financial Economics 44, 169-203.

Kothari, S.P., Shanken, J., 1992. Stock return variation and expected dividends: A time-series and cross-sectional analysis. Journal of Financial Economics 31, 177-210.

Maio, P.F., Santa-Clara, P., 2013. Dividend yields, dividend growth, and return predictability in the cross-section of stocks. Journal of Financial and Quantitative Analysis, forthcoming.

Marcus, A.A., 1981. Policy uncertainty and technological innovation. Academy of Management Review 6, 443-448.

Marsh, T.A., Merton, R.C., 1986. Dividend variability and variance bounds tests for the rationality of stock market prices. American Economic Review 76, 483-498.

Nikkinen, J., Omran, M., Sahlström, P., Äijö, J., 2006. Global stock market reactions to scheduled U.S. macroeconomic news announcements. Global Finance Journal $17,92-104$.

Ozoguz, A., 2009. Good times or bad times? Investors' uncertainty and stock returns. Review of Financial Studies 22, 4377-4422.

Pástor, L, Veronesi, P., 2012. Uncertainty about government policy and stock prices, Journal of Finance 67: 1219-1264.

Pástor, L, Veronesi, P., 2013. Political uncertainty and risk premia. CEPR discussion Papers.

Pesaran, M.H., 2004. General diagnostic tests for cross section dependence in panels, Cambridge Working Papers in Economics, No. 0435, University of Cambridge.

Pesaran, M.H., 2006. Estimation and inference in large heterogeneous panels with multifactor error structure. Econometrica 74, 967-1012.

Pesaran, M.H., Ullah, A., Yamagata, T., 2008. A bias-adjusted LM test of error cross-section independence. Econometrics Journal 11, 105-127. 
Pesaran, M.H., Yamagata, T., 2008. Testing slope homogeneity in large panels. Journal of Econometrics 142, 50-93.

Rodrik, D. (1991). Policy uncertainty and private investment in developing countries. Journal of Development Economics 36, 229-242.

Ross, S.A., 1976. The arbitrage theory of capital asset pricing. Journal of Economic Theory 13, 341-360.

Sarafidis, V., Robertson, D., 2009. On the impact of error cross-sectional dependence in short dynamic panel estimation. Econometrics Journal 12, 62-81.

Schwert, W., 1990. Stock returns and real activity: a century of evidence. Journal of Finance 45, 1237-1257.

Shiller, R.J., 1981. Do stock prices move too much to be justified by subsequent changes in dividends? American Economic Review 71, 421-436.

Sum, V., 2012. The impulse response functions of stock market returns to economic policy uncertainty. International Review of Applied Financial Issues and Economics (forthcoming).

Swamy, P.A., 1970. Efficient inference in a random coefficient regression model.

Econometrica 38, 311-323. 
Table 1 Descriptive Statistics

\begin{tabular}{lccccccc}
\hline & \multicolumn{7}{c}{ Stock Price Index } \\
\cline { 2 - 8 } Countries & Mean & Max. & \multicolumn{1}{c}{ Min. } & Std. Dev. & Skew. & Kurt. & J.-B. \\
\hline France & 4080.79 & 6053.90 & 2692.49 & 859.94 & 0.58 & 2.29 & $11.53^{* * *}$ \\
Germany & 5549.99 & 7950.70 & 2491.05 & 1394.32 & -0.20 & 2.10 & $5.94^{* *}$ \\
Italy & 27402.59 & 43823.50 & 13290.29 & 8431.69 & 0.17 & 1.92 & $7.83^{* *}$ \\
UK & 2672.85 & 3414.78 & 1747.64 & 430.57 & -0.28 & 2.06 & $7.36^{* *}$ \\
Spain & 9712.49 & 15666.30 & 5794.18 & 2412.41 & 0.63 & 2.64 & $10.72^{* * *}$ \\
Canada & 10559.68 & 14718.77 & 6156.49 & 2414.30 & -0.21 & 1.70 & $11.46^{* * *}$ \\
US & 1195.25 & 1570.70 & 757.13 & 184.88 & -0.18 & 2.41 & 2.94 \\
\hline & & & Political Uncertainty Index & & \\
Countries & Mean & Max. & Min. & Std. Dev. & Skew. & Kurt. & J.-B. \\
\hline France & 123.07 & 303.46 & 51.93 & 50.18 & 0.67 & 2.79 & $11.47 * * *$ \\
Germany & 113.41 & 253.04 & 51.76 & 36.19 & 0.96 & 4.03 & $29.08^{* * *}$ \\
Italy & 110.08 & 243.95 & 40.00 & 39.17 & 0.95 & 4.15 & $30.79 * * *$ \\
UK & 132.56 & 297.42 & 36.86 & 69.38 & 0.66 & 2.13 & $15.48 * * *$ \\
Spain & 104.17 & 241.81 & 28.33 & 40.74 & 0.70 & 3.45 & $13.51 * * *$ \\
Canada & 104.95 & 252.92 & 43.47 & 43.42 & 1.08 & 3.81 & $32.64 * * *$ \\
US & 119.75 & 246.47 & 57.52 & 40.81 & 0.48 & 2.39 & $8.04 * *$ \\
\hline
\end{tabular}

Notes: The whole sample period starts from 2001.01 and ends in 2013.04, resulting in a total of 148 monthly observations. $* *$ and $* * *$ indicate significance at the $5 \%$ and $1 \%$ levels, respectively. 
Table 2. Cross-sectional Dependence and Slope Homogeneity Tests

\begin{tabular}{|c|c|c|c|}
\hline \multicolumn{2}{|c|}{ Cross-sectional Dependence Test } & \multicolumn{2}{|c|}{ Slope Homogeneity Test } \\
\hline$C D_{B P}$ & $269.103 * * *$ & $\tilde{\Delta}$ & $1288.143 * * *$ \\
\hline$C D_{L M}$ & $38.283 * * *$ & $\tilde{\Delta}_{a d j}$ & $8.854 * * *$ \\
\hline$C D$ & $15.568 * * *$ & Swamy & $4826.793 * * *$ \\
\hline
\end{tabular}

Notes: *** indicates significance at the $1 \%$ level.

Table 3. Results for Panel Causality

\begin{tabular}{|c|c|c|c|c|c|c|}
\hline \multirow[b]{3}{*}{ Countries } & \multirow[b]{3}{*}{ Coefficient } & \multirow{3}{*}{$\begin{array}{l}\text { Wald Sta- } \\
\text { tistics }\end{array}$} & \multirow{2}{*}{\multicolumn{3}{|c|}{$\begin{array}{l}\text { Ho: Stock Index does not Granger } \\
\text { Cause Policy Index } \\
\text { Bootstrap Critical Values }\end{array}$}} & \multirow{3}{*}{$\begin{array}{c}\text { Granger } \\
\text { Causality } \\
\text { Yes/No }\end{array}$} \\
\hline & & & & & & \\
\hline & & & $10 \%$ & $5 \%$ & $1 \%$ & \\
\hline France & 0.0416 & 0.197 & 3.497 & 4.891 & 8.513 & No \\
\hline Germany & 0.0081 & 0.019 & 3.139 & 4.436 & 8.633 & No \\
\hline Italy & -0.2700 & $12.076 * * *$ & 3.388 & 4.509 & 7.841 & Yes \\
\hline UK & 0.0681 & 0.624 & 4.142 & 5.335 & 8.485 & No \\
\hline Spain & -0.281 & $6.793 * *$ & 3.189 & 4.654 & 7.938 & Yes \\
\hline Canada & 0.0557 & 0.749 & 3.120 & 4.695 & 8.237 & No \\
\hline US & 0.0380 & 0.247 & 3.315 & 4.607 & 8.351 & No \\
\hline \multirow[b]{3}{*}{ Countries } & \multirow{3}{*}{ Coefficient } & \multirow{3}{*}{$\begin{array}{l}\text { Wald Sta- } \\
\text { tistics }\end{array}$} & \multirow{2}{*}{\multicolumn{3}{|c|}{$\begin{array}{l}\text { Ho: Policy Index does not Granger } \\
\text { Cause Stock Index }\end{array}$}} & \multirow{3}{*}{$\begin{array}{c}\text { Granger } \\
\text { Causality } \\
\text { Yes/No }\end{array}$} \\
\hline & & & & & & \\
\hline & & & $10 \%$ & $5 \%$ & $1 \%$ & \\
\hline France & -0.0003 & 0.010 & 2.819 & 4.185 & 6.593 & No \\
\hline Germany & 0.0092 & 2.231 & 2.818 & 4.059 & 6.560 & No \\
\hline Italy & 0.0125 & 2.624 & 3.214 & 4.767 & 7.642 & No \\
\hline UK & 0.0071 & $7.516 * * *$ & 2.999 & 4.068 & 5.743 & Yes \\
\hline Spain & -0.0020 & 0.112 & 3.131 & 4.378 & 7.723 & No \\
\hline Canada & -0.0029 & 0.379 & 3.091 & 4.367 & 6.922 & No \\
\hline US & 0.0114 & $6.396^{* *}$ & 2.810 & 3.831 & 7.584 & Yes \\
\hline
\end{tabular}

Notes: $* *$ and $* * *$ indicate significance at the $5 \%$ and $1 \%$ levels, respectively. The bootstrap critical values were obtained from 10,000 replications. 

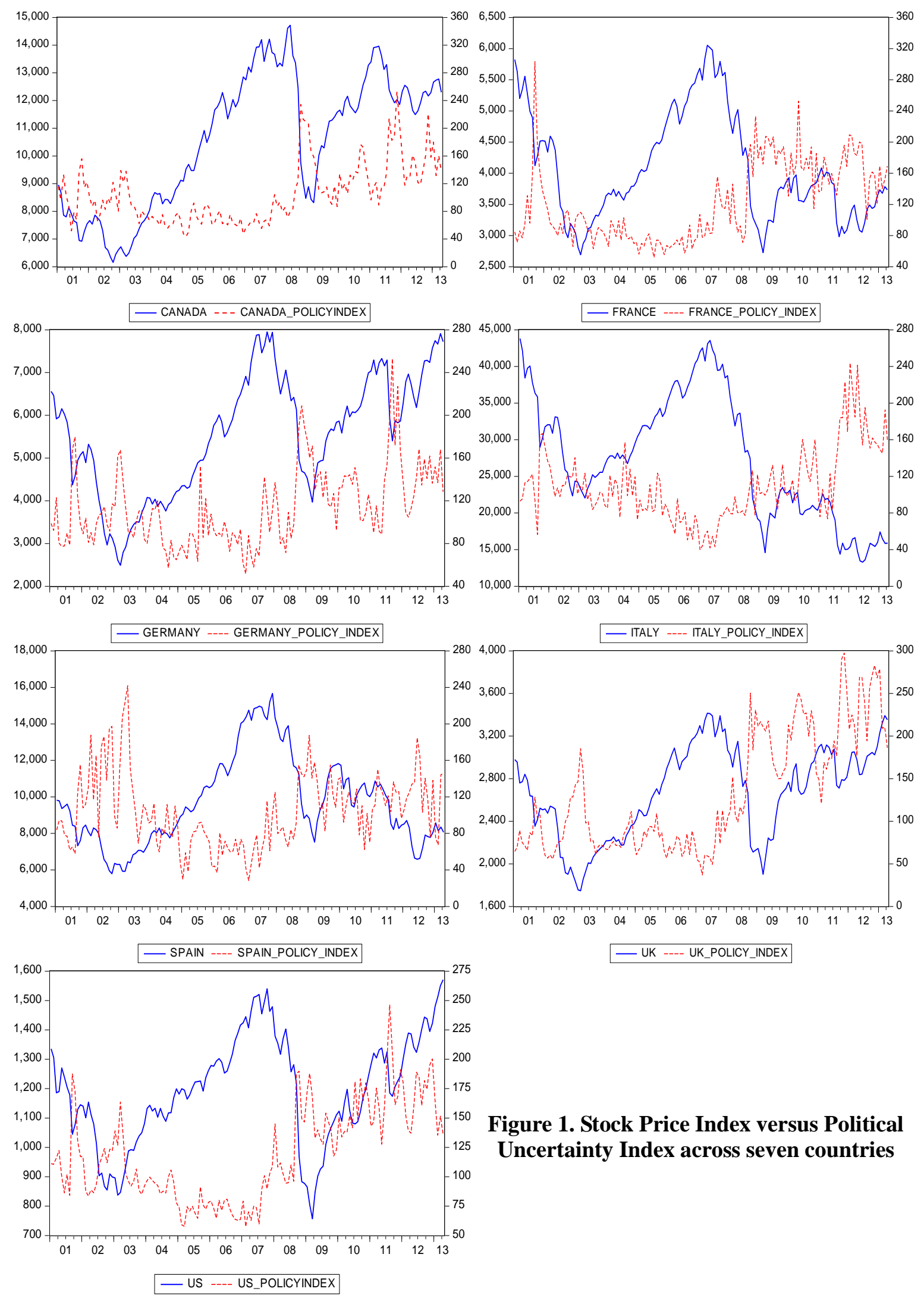

Figure 1. Stock Price Index versus Political Uncertainty Index across seven countries 